\title{
Factors of inefficient use of personal protective equipment: A survey of construction workers at Arusha urban in Tanzania
}

\author{
Yusuph Bakari Mhando* \\ Arusha Technical College, Department of Civil Engineering, Junction of Moshi-Arusha and Nairobi \\ Roads, Arusha, Tanzania
}

\begin{abstract}
Inefficient use of personal protective equipment (PPE) is generally seen by many construction industries around the world as a catalyst for increasing accidents, diseases, illness and fatalities at workplaces. The study investigates on the factors inhibiting efficient use of PPE among construction workers at Arusha urban. Data used in this study was derived from both primary and secondary sources. Secondary data was collected from a detailed review of relevant literature to the theme investigated. Primary data was collected through a structured questionnaire aimed at 60 respondents (engineers, technicians and artisans) who have knowledge and experience of construction activities. And 42 questionnaire forms were received constituting 70 per cent response rate which was considered adequate for data analysis. The rated variables were ranked with regard to their importance and occurrence. Findings revealed that business as usual and violations of work ethics were issues of concern related to factors of inefficient use of PPE. The critical factors included lack of awareness on OHS issues, inappropriate use of PPE and negligence to provide PPE respectively. It was also found that poor supervision on the use of PPE could be significant factor inhibiting efficient use of PPE. Though thermal discomfort was ranked the lowest with regard to inefficient use of PPE, it could be significant to some parts of the country with high temperature. The study suggests that there should be routine revision of OHS governing rules to respond to emerging challenges related to health and safety in the construction industry.
\end{abstract}

\section{Keywords}

Construction workers; OHS; Personal protective equipment; Safety; Tanzania

Received: 24 November 2020; Accepted: 05 March 2021

ISSN: 2630-5771 (online) (C) 2021 Golden Light Publishing All rights reserved.

\section{Introduction}

Personal protective equipment (PPE) Regulations 2002 and the PPE at work Regulations 1992 in the UK define PPE as all equipment which are intended to be worn or held by a person at work and which protects him against one or more hazards and risks to his health or safety [1]. According to Aguwa et al. [2] the use of appropriate and good quality PPE in workplaces cannot be overemphasized.
Nevertheless, PPE compliance remains low in many construction sites, even in settings where PPE are available, influencing construction workers' inability to efficiently discharge their duties. In fact, non compliance with Occupational Health and Safety (OHS) issues in construction sites, particularly inefficient use of PPE have led to great risk of injuries, illness and fatalities to hundreds of construction workers, predominantly in developing

\footnotetext{
* Corresponding author

Email:ybmhando@gmail.com
} 
countries. Arguably, every day, a new labor force of skilled and unskilled enters the construction industry lacking adequate knowledge on issues relating to OHS. This scenario obliges the need to increase awareness on efficient use of PPE in endeavoring to improve health and safety in construction sites. Chiocha et al. [3] insist that there is a need to raise the level of health and safety awareness in developing countries because recent findings suggest that in developing countries such as Botswana construction health and safety awareness is low.

Certainly, several studies were carried out on issues relating to health and safety at workplaces. According to [4] there are many studies which examine the work safety and work accidents in the construction industry. However, most of these studies were not able to demonstrate clearly as to why there is inefficient use of PPE in construction sites. Evidently, previous studies such as [5] was not able to collect primary data to better measure resources committed to OHS as well as the policies, procedures and practices the resources are intended to influence. Additionally, these researches have inadequately examined the major causes of inefficient use of PPE amongst construction workers. These studies include [6] who found that architectural designers in South Africa inadequately address construction health and safety during the design process. Mrema et al. [7] investigated status of occupational health and safety in expanding economy of Tanzania and found that hazards emanating from work in all sectors of the economy have increased and varied. Others are [8] who managed to find out that poor site management and failures to use PPE were among the factors contributing to poor safety practices in Cape Coast Metropolis in Ghana while [9] concluded that contractors rarely provide PPE to construction workers in South Africa. Markedly, while recommendations from those previous studies were beneficial, they are not sufficient to address issues on health and safety relating to PPE use, fueling the need to look comparatively the critical factors barricading effective use of PPE in construction sites in other countries.
In fact, research on OHS issues, particularly in the use of PPE in construction sites is still low. Phoya [10] insists that no adequate data on health and safety risk assessment, communication and control related to construction in Tanzania. Moreover, Kibwami and Mbuya [11] point out that construction sector is an economy sector associated with proportionately many accidents, injuries and diseases as compared to other sectors, yet there is a paucity of research on issues relating to OHS in the context of Tanzania. The objective of this study was to examine major factors impeding efficient use of PPE in construction sites in Arusha urban with the view to suggest policy measures to increase awareness on the effective use of PPE in the construction industry. The study results promote the need to increase awareness on the use of PPE among construction workers. The findings would help construction practitioners and policy makers to improve health and safety in construction sites. The rest of the paper presents a literature review, methods, discussions and conclusions sections to summarize the themes and main contributions of the study.

\section{Literature review}

\subsection{Overview of OHS practice in Tanzania}

OHS practice in Tanzania is governed by the OHS Act [12]. The key features of the Act include: introduction of health and safety representatives and committees of workers at construction sites; employers are legally responsible for providing health and safety training to workers including information on hazards inherent in the work; the Act has powers to compound offences; and preparation of health and safety policy and code of practice [12]. Though this OHS Act is currently in place and is the main Legislation governing OHS practices in Tanzania, still there are soaring risk of diseases, accidents and injuries in the construction sector. This scenario affirms that the OHS Regulations in Tanzania could be far from performing well. In fact, to provide employees with safe working conditions, it is necessary to introduce appropriate legal regulations [13]. 


\subsection{Use of personal protective equipment (PPE)}

The use of appropriate and good quality PPE in workplaces cannot be overemphasized [2]. PPE are designed to protect employees from serious workplace injuries or illnesses resulting from contact with chemical, radiological, physical, electrical, mechanical, or other workplace hazards [2]. Though it is safer and in most cases cheaper to prevent occurrence of accidents rather than providing PPE to guard against it, utilization of PPE efficiently is inevitable as last line of defense in control measures to reduce the possibilities for accidents to happen. Mansour et al. [1] argue that PPE are used as the last measure for workplace hazards control and are used in the case where managerial and engineering control measures are already in place.

PPE includes items such as gloves, goggles, respirators, earplugs, hard hats, knee coverings, face shields, full body covers, safety footwear, and safety harnesses. Dharani et al. [14] affirm that PPE involves item such as foot and hand protection, eye protection, head protection, ear protection and body protection. Nevertheless, compliance to health and safety measures remains noticeably low in construction sites, particularly in developing countries. Unfortunately, employers of construction workers in urban areas are mostly ordinary house owners, rather than contractors or subcontractors. These house owners they consider provision of PPE to construction workers as burden, and not feel responsible for the health and safety of their workers. Previous studies $[14,15]$ insist that employers or contractors are responsible for providing, replacing and paying for PPE to ensure health and safety of workers. On the other hand, Sawada et al. [16] point out that, though many types of PPE have been developed to tackle the problem of health and safety in industries, their effectiveness and usability still remain incomplete. Vitharana et al. [17] insist that safety in construction sites needs to be highly considered in order to reduce the risk of persons being injured at work.

\subsection{Factors impeding use of PPE}

Factors impeding efficient use of PPE among construction workers were reported in many previous studies. Lack of training on the use of PPE, lack of management in supporting the safety culture, inappropriate use and maintenance of PPE, and employer failure to provide PPE were reported to be the causes of inefficient use of PPE in Malaysia [15]. Okwabi et al. [18] and Kralam et al. [19] found that poor knowledge on the usefulness of PPE, lack of law enforcement of safety practice, and poor attitudes towards safety practices were the significant factors of inefficient use of PPE in Ghana and Thailand respectively. Moreover, many workers in the United States (US), particularly across the Southeast Region, do not feel wearing PPE is essential to their health [20]. From review of previous studies carried out by $[15,20,21]$ and other researchers presented in Table 1, a total of 5 major factors that impede effective use of PPE were identified and formulated the basis of the second part of questionnaire administered to construction workers. The next section discusses research methodology and data analysis techniques used for the study

\section{Materials and methods}

\subsection{Location of study area}

Arusha urban is situated in northern Tanzania, just below Mount Meru at an elevation of $1,500 \mathrm{~m}$ above the sea level [25]. The city has a total land area of 267 square kilometers. Arusha urban is divided into 19 wards, 3 divisions (Elerai, Suye and Themi) and Arusha Constituency [25].

Table 1. Significant factors impeding use of PPE

\begin{tabular}{ll}
\hline Significant impediment factors & Author(s) \\
\hline Lack of awareness on OHS issues & {$[15,18,19,22]$} \\
Poor supervision on the use of PPE & {$[20]$} \\
Inappropriate use of PPE & {$[15]$} \\
Negligence to provide PPE & {$[15,22,23]$} \\
Thermal discomfort & {$[21,24]$} \\
\hline
\end{tabular}


Arusha City is between $03^{\circ} 22^{\prime} 21^{\prime \prime}$ South latitude and $36^{\circ} 41^{\prime} 40^{\prime \prime}$ East latitude along the slopes of Mount Meru. The city is experiencing high rate of urbanizations resulting into a considerable growth of construction activities. The estimated total population of Arusha City is 416, 442 [26].

\subsection{Research design}

The research design of the study was a survey conducted in order to empirically validate the factors impeding efficient use of PPE among construction workers. Creswell [27] clarifies that research designs are plans and procedures for research that span the decisions from broad assumptions to detailed methods of data collection and analysis. A judgmental (purposive) sampling technique was used in this study. Kombo and Tromp [28] argue that judgmental sampling is a powerful technique for selecting objects for the study. They further insist that the power of judgmental sampling technique lies in selecting information rich cases for in-depth analysis related to the central issues being studied, and it can be used with both quantitative and qualitative studies. In this study, a total of 60 structured questionnaire forms were purposely distributed to 8 engineers, 18 technicians and 34 artisans contacted in person to get individual perspectives from which 42 properly filled questionnaire forms have been returned. During data collection, face to face approaches were used to remind the respondents to fill the questionnaire form. Table 2 shows that 3(36\%) engineers, $13(72 \%)$ technicians and 26(76\%) artisans constituted $42(70 \%)$ valid responses of which was considered adequate for data analysis.

Basically, in this study, both primary and secondary data were used for the survey. The primary data were those collected from respondents. Conversely, secondary data were those from reviewed relevant literature such as scientific publications from reputable journals, websites of relevant themes and some textbooks that became helpful in building the context of the study. In the pre-testing phase, a judgement sample of 14 respondents with good spread of respondents' characteristics was chosen for the pre-testing of the questionnaire. Nevertheless, only 8 valid responses were received from respondents constituting 57\% of which was considered adequate for validation. From the feedback received, minor corrections were made to improve questions, layout, format and the contents to validate the questionnaire prior to main survey. The validated structured questionnaire comprised two sections; the first section was designed to seek for the general information about the respondents related to experience in the field, gender and professional status. The second part was for respondents to rate variables regarding factors that impede efficient use of PPE among workers in construction sites. In this case, 5-Point Likert scale ( strongly disagree $=1$; disagree $=2$; neutral $=3$; agree $=4$ and strongly agree $=5$ ) were used to rate the variables in the questionnaire. Previous researchers [29, 30] have successful used Likert scale rating system in their studies.

\subsection{Data analysis}

Statistical Package for Social Sciences (SPSS) was employed to process the data [31]. Data were carefully analysed statistically using descriptive statistics, frequencies, Cronbach's alpha reliability test and principal component analysis (PCA) to draw inferences.

Table 2. Distribution of respondents involved in the survey

\begin{tabular}{lccc}
\hline Category of Participants & $\begin{array}{c}\text { No. of questionnaire } \\
\text { forms sent }\end{array}$ & $\begin{array}{c}\text { No. of questionnaire } \\
\text { forms returned }\end{array}$ & $\begin{array}{c}\% \text { of Questionnaire forms } \\
\text { returned }\end{array}$ \\
\hline Engineers & 8 & 3 & $36 \%$ \\
Technicians & 18 & 13 & $72 \%$ \\
Artisans & 34 & 26 & $76 \%$ \\
Total & 60 & 42 & $70 \%$ \\
\hline
\end{tabular}


In the process of PCA, Varimax orthogonal rotation, extraction, Kaiser-Meyer-Olkin (KMO), Bartlett's test, Eigenvalues, correlation matrix and Scree plot were applied to explore and understand the underlying relationships of the rated variables in this study. Table 3 illustrates that the calculated Cronbach's alpha coefficient value for the rated items of the questionnaire was 0.719. This reliability value demonstrated that the results from the survey are acceptable such that they provide proper ground for further analysis. Reliability is the total consistency of a certain measure [32].

According to Wim et al. as cited in [32] a value of Cronbach's alpha between 0.6 and 0.8 is acceptable. Furthermore, generated frequencies resulted from a five-point Likert scale ranging from 1 (strongly disagree) to 5 (strongly agree) were used to calculate mean item score (MIS) for each of the factors inhibiting efficient use of PPE in construction sites as assessed by the respondents. The MIS values were then used to determine the rank of each item in descending order (from the highest to the lowest) of their mean item score. The ranking enabled the researcher to cross compare the relative importance of the items as perceived by the respondents. The MIS was calculated by using equation 1. MIS approach has been used by many researchers including [33, 34].

$$
M I S=\frac{1 n 1+2 n 2+3 n 3+4 n 4+5 n 5}{\sum N}
$$

where $\mathrm{n} 1, \mathrm{n} 2, \mathrm{n} 3, \mathrm{n} 4, \mathrm{n} 5$ and $\mathrm{N}$ are number of respondents for strongly disagree, number of respondents for disagree, number of respondents for neutral, number of respondents for agree, number of respondents for strongly agree and total number of respondents, respectively.

Table 3. Cronbach's Alpha reliability statistics

\begin{tabular}{lll}
\hline \multicolumn{3}{c}{ Reliability Statistics } \\
\hline $\begin{array}{ll}\text { Cronbach's } \\
\text { Alpha }\end{array}$ & $\begin{array}{l}\text { Cronbach's Alpha } \\
\text { Based on Standardized } \\
\text { Items }\end{array}$ & N of Items \\
\hline .719 & .700 & 12 \\
\hline
\end{tabular}

\subsection{Research framework}

The identified dependent variable in this study is inefficient use of PPE on construction sites. The independent variables in this scientific study are the factors of inefficient use of PPE on construction sites. The factors of inefficient use of PPE included in the independent variables are lack of awareness on OHS issues, poor supervision on the use of PPE, inappropriate use of PPE, negligence to provide PPE and thermal discomfort.

\section{Results and discussion}

\subsection{Respondents' characteristics}

Respondents were categorised in terms of gender and work experience as shown in Table 4 . Result shows that $36(86 \%)$ were male and $6(14 \%)$ were female. These statistics indicate that most activities on construction sites are carried out by men. In their study, Sospeter et al. [35] found that women continue to be under-represented in the Tanzanian construction industry. The determined average of 15 years of work experience of respondents was considered suitable such that the responses given by those construction workers were considered reliable and trustworthy. Moreover, $41 \%$ of 42 participants have been in the construction activities for a period of 1-5years. This is still worthwhile for the study because the experience suggests most participants might have been involved in construction projects not less than three years.

\subsection{Factors inhibiting effective use of PPE}

Table 5 shows the ranking of the factors of inefficient use of PPE based on the weighted average of relative importance indices (MIS). As a result, majority of the respondents agreed that lack of awareness on OHS issues ( $\mathrm{MIS}=4.33 ; \mathrm{R}=1$ ) was the most critical factor of inefficient use of PPE on construction sites followed by negligence to provide PPE (MIS = 3.64; $\mathrm{R}=2$ ). Other factors explored were inappropriate use of PPE (MIS = $3.62 ; \mathrm{R}=3$ ) and poor supervision on the use of PPE $(\mathrm{MIS}=3.52 ; \mathrm{R}=4)$. 
Table 4. Demographic of respondents

\begin{tabular}{llccc}
\hline & Characteristics & Frequency & Percentage & Cumulative Percentage \\
\hline \multirow{3}{*}{ Sex } & Male & 36 & 86 & 86 \\
& Female & 6 & 14 & 100 \\
\cline { 2 - 5 } & Total & 42 & 100 & 41 \\
\hline \multirow{3}{*}{ Work Experience } & $1-5$ years & 17 & 41 & 65 \\
& $6-10$ years & 10 & 24 & 79 \\
& $16-20$ years & 6 & 14 & 93 \\
& $21-25$ years & 6 & 14 & 100 \\
& More than 25 years & 3 & 7 & 100 \\
\cline { 2 - 5 } & Total & 42 & 100 & 10 \\
\hline
\end{tabular}

Table 5. Critical factors inhibiting effective use of PPE

\begin{tabular}{lcc}
\hline Factors of inefficient use of PPE & Mean Item Score (MIS) & Rank (R) \\
\hline Lack of awareness on OHS issues & 4.33 & 1 \\
Negligence to provide PPE & 3.64 & 2 \\
Inappropriate use of PPE & 3.62 & 3 \\
Poor supervision on the use of PPE & 3.52 & 4 \\
Thermal discomfort & 3.33 & 5 \\
\hline
\end{tabular}

However, from viewpoints of the respondents, thermal discomfort (MIS $=3.33 ; \mathrm{R}=5$ ) was ranked the lowest. Basically, respondents have agreed that all five rated factors hindering efficient use of PPE were significant since their MIS values were greater than 3. These results correlate with the works of the previous researchers $[15,18,19,22,23]$ who found lack of management in supporting the safety culture, inappropriate use and maintenance of PPE, employer failure to provide PPE, poor knowledge on the usefulness of PPE, lack of law enforcement of safety practice, and poor attitudes towards safety practices as significant factors of inefficient use of PPE in Malaysia, Ghana, Thailand, Bangladesh and Cambodia respectively. Mustapha et al. [8] reveal that insufficient OHS education is a potential factor impeding use of PPE in Ghana. Okwabi et al. [18] insist that there are poor attitudes toward safety practices, as workers are not really concerned about their personal protection. In their study, Opaleye et al. [9] found that neglect on workers safety, employment of incompetent foremen and safety personnel by the main contractors, unsafe behaviour of workers on site, inadequate provision of PPE to workers on site are the factors impeding appropriate use of PPE in South Africa. Interestingly, thermal discomfort (MIS $=3.33 ; \mathrm{R}=$ 5) was the lowest with regard to inefficient use of PPE in Arusha region. Arguably, this could be due to the fact that Arusha region has favorable moderate temperature. However, it could be significant to some parts of the country characterized with high temperature such as Dar es Salaam, Tanga and Coast regions in Tanzania. Zuofa and Ochieng [24] found that during the dry season, the weather at times is extremely hot, so it becomes difficult for some of construction workers to even want to use PPE given to them.

\subsection{Principal component analysis}

Principal Component Analysis (PCA) was carried out by using Varimax Orthogonal Rotation Criteria (VORC) to explore and understand the underlying relationships of the rated variables. PCA has been 
used successfully by many researchers such as [29, 30] in their studies. It is argued that, a KaiserMeyer-Olkin (KMO) value close to 1 indicates that the patterns of correlations are relatively compact and so, factor analysis should yield distinct and reliable factors. Table 6 shows that the determined value from KMO test was 0.52 of which is acceptable since it is over 0.5 . On the other hand, the determined approximate Chi-square value from the Bartlett's test of sphericity was 54.27, degree of freedom was 21 and the test was significant at 0.00 that led to null hypothesis been rejected. These ascertained values provide confidence that the conducted factor analysis was appropriate and the variables were correlated highly enough to provide a reasonable basis for factor analysis. Moreover, Table 7 demonstrates that the Eigenvalues is over 1 when there are 2 components. The cumulative percentage of variance also shows $64.867 \%$ for the 2 components which is above the required minimum of $60 \%$ as advocated by Hair et al. in [36]. Furthermore, the determined values from Table 7 demonstrate that it is logical to take two components or factors for consideration. Fig. 1 shows a Scree plot from principal component analysis which supports this scientific decision to consider two components. The Scree plot shows that there are five components where the first two indicate that their Eigenvalues are greater than 1. Additionally, analysis results in Table 8 show the factor loadings, where two factors (components) were developed. The developed two factors were assigned appropriate variables. Factor-1 includes negligence to provide PPE, lack of awareness on OHS issues and poor supervision on the use of PPE. Factor-2 comprises thermal discomfort and inappropriate use of PPE.

Table 9 demonstrates that business as usual on OHS issues and violations of work ethics were the two significant reasons that inhibit efficient use of PPE among construction workers. These scenarios indicate that the level of health and safety awareness in the context of construction industry in Tanzania is still low. Business as usual on OHS issues and violations of work ethics support the work done by $[18,19,22]$ who found that poor knowledge on the usefulness of PPE, lack of law enforcement of safety rules and regulations, lack of safety awareness among the construction stakeholders, and poor attitudes towards safety practices were the significant factors of inefficient use of PPE.

Table 6. Bartlett's test and KMO for the factors

\begin{tabular}{lrc}
\hline \multicolumn{3}{c}{ KMO and Bartlett's Test } \\
\hline Kaiser-Meyer-Olkin Measure of Sampling Adequacy. & .52 \\
\hline & Approx. Chi-Square & 54.27 \\
Bartlett's Test of Sphericity & df & 21 \\
& Sig. & .00 \\
\hline
\end{tabular}

Table 7. Components from total variance explained

\begin{tabular}{|c|c|c|c|c|c|c|c|c|c|}
\hline \multirow{2}{*}{ 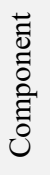 } & \multicolumn{3}{|c|}{ Initial Eigenvalues } & \multicolumn{3}{|c|}{$\begin{array}{l}\text { Extraction Sums of Squared } \\
\text { Loadings }\end{array}$} & \multicolumn{3}{|c|}{ Rotation Sums of Squared Loadings } \\
\hline & Total & $\begin{array}{c}\% \text { of } \\
\text { Variance }\end{array}$ & $\begin{array}{c}\text { Cumulative } \\
\%\end{array}$ & Total & $\begin{array}{c}\% \text { of } \\
\text { Variance }\end{array}$ & $\begin{array}{c}\text { Cumulative } \\
\%\end{array}$ & Total & $\begin{array}{c}\% \text { of } \\
\text { Variance }\end{array}$ & $\begin{array}{c}\text { Cumulative } \\
\%\end{array}$ \\
\hline 1 & 1.750 & 35.005 & 35.005 & 1.750 & 35.005 & 35.005 & 1.628 & 32.561 & 32.561 \\
\hline 2 & 1.493 & 29.861 & 64.867 & 1.493 & 29.861 & 64.867 & 1.615 & 32.305 & 64.867 \\
\hline 3 & .918 & 18.355 & 83.221 & & & & & & \\
\hline 4 & .481 & 9.621 & 92.842 & & & & & & \\
\hline 5 & .358 & 7.158 & 100.000 & & & & & & \\
\hline
\end{tabular}

Extraction method: Principal component analysis 


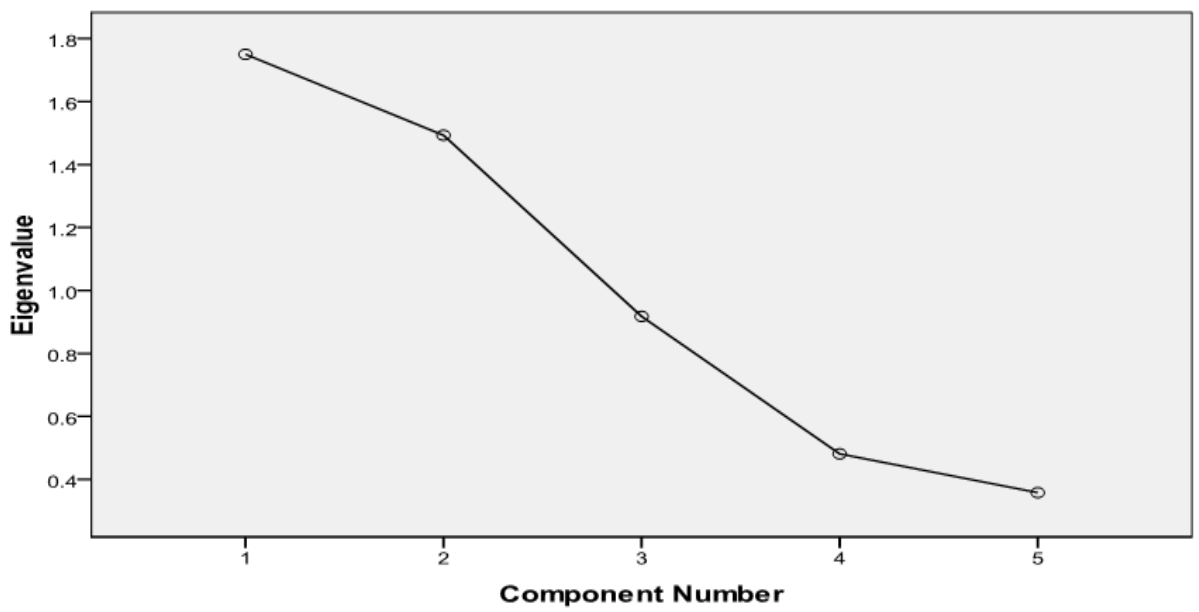

Fig. 1. Scree plot from principal component analysis

Table 8. Results of factor analysis showing the factor loadings

\begin{tabular}{lcc}
\hline & Rotated Component Matrix & \\
\hline & \multicolumn{2}{c}{ Component } \\
\cline { 2 - 3 } & 1 & 2 \\
\hline Negligence to provide PPE & $\mathbf{. 8 5 5}$ & .093 \\
Lack of awareness and, or training on OHS & $\mathbf{. 7 2 5}$ & -.257 \\
Poor supervision on the use of PPE & $\mathbf{. 6 0 2}$ & .331 \\
Thermal discomfort & -.036 & $\mathbf{. 9 0 5}$ \\
Inappropriate use of PPE & .088 & $\mathbf{. 7 8 3}$ \\
\hline
\end{tabular}

Extraction Method: Principal Component Analysis.

Rotation Method: Varimax with Kaiser Normalization.

a. Rotation converged in 3 iterations

Table 9. Developed two factors with their appropriate variables

\begin{tabular}{ll}
\hline Factor 1 & Factor 2 \\
\hline Business as usual on OHS issues & Violations of work ethics \\
1. Negligence to provide PPE & 1. Thermal discomfort \\
2. Lack of awareness on OHS & 2. Inappropriate use of PPE \\
3. Poor supervision on the use of PPE & \\
\hline
\end{tabular}

In fact, literature reviewed shows that there is an ongoing and unchanging state of affairs with regard to OHS issues despite the soaring risk of accidents, injuries and diseases in the construction industry. Arguably, the construction industry is among the fastest growing and expanding economic sectors in the country, however, many accidents and diseases occur in the industry [7].

\section{Limitations of the study}

The study was confined on construction sites in Arusha urban and the sample size of the study was 60 participants with response rate of $42(70 \%)$. 
These could be considered as some limitations to the study. Despite these limitations, the findings of this study represent a snapshot of the factors that hinder effective use of personal protective equipment among building construction workers.

\section{Conclusion and recommendations}

The study was to examine major factors impeding efficient use of PPE in construction sites in Arusha urban, with the view to suggest policy measures to increase awareness on the effective use of PPE in the construction industry. Construction industry is among the fastest growing and expanding economic sectors in Tanzania. This is evidenced by the ongoing mega infrastructure projects such as the Tanzania Standard Gauge Railway Project (SGR), the country's biggest ever infrastructure project, and the Julius Nyerere Hydropower Station Project (JNHS). Thus, the concept of OHS in construction activities in this study has shown that business as usual and violations of work ethics related to health and safety practice exist and are leading to great risk of accidents, diseases, illness and fatalities to hundreds of construction workers, predominantly in developing countries. Literature further revealed that there is a need to raise the level of health and safety awareness in developing countries to enhance best practice of OHS in construction activities. Empirical findings revealed that business as usual and violations of work ethics are issues of concern related to factors of inefficient use of PPE. The factors include lack of awareness on OHS, inappropriate use of PPE and negligence to provide PPE. Markedly, effective use of PPE in construction sites should be seen as a catalyst for minimizing accidents, diseases, illness and fatalities with the intention of improving the health and safety of construction workers. Based on the research objective, the study recommends the following to practitioners, researchers and policies governing the OHS in the construction industries:

- Business as usual on OHS issues should be absolutely discouraged. This would encourage revision of occupational health services and OHS governing rules to respond to emerging challenges related to health and safety in the construction industry.

- Training on OHS issues to practicing architects, engineers, quantity surveyors, land surveyors, project managers, supervisors, technicians, artisans, laborers and other construction stakeholders is necessary in raising the level of health and safety awareness in construction activities.

- Construction stakeholders should show high commitment towards the application of PPE all the time when undertaking construction activities. This would help to reduce violations of work ethics and enhance health and safety of construction workers.

- Occupational Safety and Health Authority (OSHA) and other relevant stakeholders should strongly support capacity building through $R \& D$ programmes to promote research culture on occupational health and safety. This would help to build effective institutional framework in enhancing OHS in the construction industry.

- Government through OSHA and relevant partners should commit enough funds to enhance workrelated safety and health activities in the construction industry.

- Further research is suggested in developing an appropriate approach of capturing information related to OHS issues.

\section{Ethics committee permission}

The author confirms that no ethics committee permit was required in Tanzania for data collection through questionnaire. However, special permission and consent was sought and obtained from the respondents before they were given the questionnaire to respond, with the condition for their responses being processed, analyzed and published without revealing their identities.

\section{Declaration of conflicting interests}

The author(s) declared no potential conflicts of interest with respect to the research, authorship, and/or publication of this article. 


\section{Acknowledgments}

The author wish to gratefully acknowledge, with thanks, the Arusha City Council (ACC), contractors, workers in construction sites for providing data needed. The collected data enabled the preparation of this scientific research manuscript.

\section{References}

[1] Mansour A, Balkhyour MA, Ahmad I, Rehan M (2018) Assessment of personal protective equipment use and occupational exposures in small industries in Jeddah: Health implications for workers. Saudi Journal of Biological Sciences, 26: 653-659.

[2] Aguwa EN, Arinze-Onyia SU, Ndu A (2016) Use of personal protective equipment among health workers in a tertiary health institution, South East Nigeria: Pre-ebola period. International Journal of Health Sciences and Research, 6(8): 12-18.

[3] Chiocha C, Smallwood J, Emuze F (2011) Health and safety in the Malawian construction industry. Acta Structilia, 18(1): 68-80.

[4] Yılmaz GK, Başağa HB (2018) Assessment of occupational accidents in construction sector. A case study in Turkey. Journal of Construction Engineering, Management \& Innovation, 1(2): 95107.

[5] Amick BC, Hogg-Johnson S, Latour-Villamil D, Saunders R (2015) Protecting construction worker health and safety in Ontario, Canada: identifying a union safety effect. Journal of Occupational and Environmental Medicine, 57(12): 1337-1342.

[6] Goldswain G, Smallwood J. Mitigating construction health, safety, and ergonomic risks: perceptions of architectural design professionals. TG59 People in Construction Conference Proceedings, 12-14 July 2009, Port Elizabeth, South Africa.

[7] Mrema EJ, Ngowi AV, Mamuya SHD (2015) Status of occupational health and safety and related challenges in expanding economy of Tanzania. Annals of Global Health, 81(4): 538-547.

[8] Mustapha Z, Aigbavboa C, Thwala WD. Occupational health and safety challenges in the Ghanaian construction industry. Proceedings of the Fourth Construction Management conference, 30th November-1st December 2015, Port Elizabeth, South Africa.
[9] Opaleye O, Smallwood J, Shakantu W. Evaluating causes of workers' accident on small scale construction sites in Pretoria. Proceedings of the Fourth Construction Management Conference, 30th Nov -1st Dec 2015, Port Elizabeth, South Africa.

[10] Phoya S. Engineering health and safety risk management in building construction sites in Tanzania: The practice of risk assessment, communication and control. Licentiate Thesis, Chalmers University of Technology, 2012.

[11] Kibwami N, Mbuya E. Analysis of the draft policy on occupational safety and health (OSH): Tanzaniaconstruction industry. Proceedings TG5 People in Construction, 12-14 July 2009, Port Elizabeth, South Africa.

[12] OSHA. Occupational health and safety Act. Government printer, Dar es Salaam, 2003. https://www.osha.go.tz/page/laws-and-regulations. Accessed: 26.12.2019.

[13] Bazan-Bulanda A (2019) Impact of occupational health and safety regulations on the employee's decision to take up employment. System Safety:Human-Technical Facility Environment, 1(1): 141-148.

[14] Dharani R, Sivalingam A, Prabhakaran D, Thirumarimurugan MA (2015) Study on prevention of hazard in industry by the use of personal protective equipment and implementing smart technology for personal protective equipment. International Research Journal of Engineering and Technology, 02(08): 1005-1007.

[15] Ulang N, Salim NS, Baharum F, Agus SNA. Construction site workers' awareness on using safety equipment: Case study. Building Surveying, Facilities Management and Engineering Conference, 27 August 2014, Seri Iskandar, Perak, Malaysia.

[16] Sawada S, Kuklane K, Wakatsuki K, Morikawa H (2017) New development of research on personal protective equipment for occupational safety and health. Industrial Health, 2(55): 471-472.

[17] Vitharana VHP, Subashi De Silva GHMJ, Sudhira De Silva (2015) Health hazards, risk and safety practices in construction sites-a review study. Engineer, XLVIII(03): 35-44.

[18] Okwabi R, Agyemang S, Nyanor P (2016) Assessment of informal sector garages workers' safety awareness at the Odorna garages in Accra, Ghana. International Journal of Scientific and Research Publications, 6(5): 212-216. 
[19] Kralam K, Taneepanichskul N (2016) Knowledge, attitude and practice towards personal protectiveequipment use among steel industry workers in Thailand. Journal of Health Research, 30(suppl.2):161-165.

[20] Wright T, Adhikari A, Yin J, Vogel R, Smallwood S, Shah G (2019) Issue of compliance with use of personal protective equipment among wastewater workers across the southeast region of the United States. International Journal of Environmental Research and Public Health, 16: 1- 18.

[21] Almeidaa RACS, Veigab MM, Duartec FJCM, Meirellesc LA, Veigac LBE (2012) Thermal comfort and personal protective equipment. Work, 41: 4979-4982.

[22] Hossain M, Ahmed S (2018) A case study on safety assessment of construction project in Bangladesh. Journal of Construction Engineering, Management and Innovation, 1(4): 147-156.

[23] Durdyev S, Mohamed S, Lay ML, Ismail S (2017) Key Factors Affecting Construction Safety Performance in Developing Countries: Evidence from Cambodia. Construction Economics and Building, 17(4): 48-65.

[24] Zuofa T, Ochieng EG. Enhancing safety: lessons from senior managers in the Nigerian construction industry. Proceedings 6th West Africa Built Environment Research (WABER) conference, 1012 August 2015, Accra, Ghana.

[25] Arusha City Council (ACC). The history of Arusha city council. http://www.arushacc.go.tz/. Accessed: 23.09.2020.

[26] National Bureau of Statistics (NBS). Population and housing census for the united republic of Tanzania. Government Printer, Dar es Salaam, 2012.

https://www.nbs.go.tz/index.php/en/censussurveys /population-and-housing-census. Accessed: 23.09.2020.

[27] Creswell JW. Research Design: Qualitative, Quantitative and Mixed Methods Approaches, SAGE Publications, London, 2009.

[28] Kombo DK, Tromp DLA. Proposals and Thesis Writing: An Introduction. Pauline's publications Africa, Nairobi, 2006.
[29] Memon AH, Rahman IA, Hasan MFA (2014) Significant causes and effects of variation orders in construction projects. Research Journal of Applied Sciences, Engineering and Technology, 7(21): 4494-4502.

[30] Ikediashi DI, Ogunlana SO, Alotaibi A (2014) Analysis of project failure factors for infrastructure projects in Saudi Arabia: A multivariate approach. Journal of Construction in Developing Countries, 19(1): 35-52.

[31] Al-Zwainy FMS, Hadhal NT (2016) Building a mathematical model for predicting the cost ofthe communication towers projects using multifactor linear regression technique. International Journal of Construction Engineering and Management, 5(1): 25-29.

[32] Hajjar STE (2018) Statistical analysis: internalconsistency reliability and construct validity. International Journal of Quantitative and Qualitative Research Methods, 6(1): 27-38.

[33] Sibiya M, Aigbavboa C, Thwala W (2015) Measures to improve the performance of construction projects in South Africa. Proceedings 6th West Africa Built Environment Research (WABER) Conference, 10-12 August 2015, Accra, Ghana.

[34] Kekana K, Aigbavboa C, Thwala W (2015) Strategies to facilitate Building Information Modelling adoption in the South African construction industry. Procs 6th West Africa Built Environment Research (WABER) Conference, 1012 August 2015, Accra, Ghana.

[35] Sospeter NG, Rwelamila PD, Nchimbi M, Masoud M (2014) Review of theory and practice literature on women entrepreneurship in the Tanzanian construction industry: Establishing the missing link. Journal of Construction in Developing Countries, 19(2): 75-85.

[36] Chan DWM, Hung HTW (2015) An empirical survey of the perceived benefits of implementing the mandatory building inspection scheme (MBIS) in Hong Kong. Facilities Journal, 33(5/6): 337-366 